NASA/TM-1999-208851

\title{
Technology Projections for Solar Dynamic Power
}

Lee S. Mason

Lewis Research Center, Cleveland, Ohio 
Since its founding, NASA has been dedicated to the advancement of aeronautics and space science. The NASA Scientific and Technical Information (STI) Program Office plays a key part in helping NASA maintain this important role.

The NASA STI Program Office is operated by Langley Research Center, the Lead Center for NASA's scientific and technical information. The NASA STI Program Office provides access to the NASA STI Database, the largest collection of aeronautical and space science STI in the world. The Program Office is also NASA's institutional mechanism for disseminating the results of its research and development activities. These results are published by NASA in the NASA STI Report Series, which includes the following report types:

- TECHNICAL PUBLICATION. Reports of completed research or a major significant phase of research that present the results of NASA programs and include extensive data or theoretical analysis. Includes compilations of significant scientific and technical data and information deemed to be of continuing reference value. NASA's counterpart of peerreviewed formal professional papers but has less stringent limitations on manuscript length and extent of graphic presentations.

- TECHNICAL MEMORANDUM. Scientific and technical findings that are preliminary or of specialized interest, e.g., quick release reports, working papers, and bibliographies that contain minimal annotation. Does not contain extensive analysis.

- CONTRACTOR REPORT. Scientific and technical findings by NASA-sponsored contractors and grantees.
- CONFERENCE PUBLICATION. Collected papers from scientific and technical conferences, symposia, seminars, or other meetings sponsored or cosponsored by NASA.

- SPECIAL PUBLICATION. Scientific, technical, or historical information from NASA programs, projects, and missions, often concerned with subjects having substantial public interest.

- TECHNICAL TRANSLATION. Englishlanguage translations of foreign scientific and technical material pertinent to NASA's mission.

Specialized services that complement the STI Program Office's diverse offerings include creating custom thesauri, building customized data bases, organizing and publishing research results ... even providing videos.

For more information about the NASA STI Program Office, see the following:

- Access the NASA STI Program Home Page at http://www.sti.nasa.gov

- E-mail your question via the Internet to help@sti.nasa.gov

- Fax your question to the NASA Access Help Desk at (301) 621-0134

- Telephone the NASA Access Help Desk at (301) 621-0390

- Write to:

NASA Access Help Desk

NASA Center for AeroSpace Information 7121 Standard Drive

Hanover, MD 21076 
NASA/TM-1999-208851

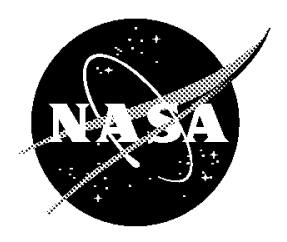

\section{Technology Projections for Solar Dynamic Power}

Lee S. Mason

Lewis Research Center, Cleveland, Ohio

Prepared for the

Space Technology and Applications International Forum cosponsored by the Boeing Company, Lockheed Martin, National Aeronautics and Space Administration, U.S. Air Force, and the U.S. Department of Energy Albuquerque, New Mexico, January 31-February 4, 1999

National Aeronautics and Space Administration

Lewis Research Center 
Available from

NASA Center for Aerospace Information 7121 Standard Drive

Hanover, MD 21076

Price Code: A03
National Technical Information Service 5285 Port Royal Road Springfield, VA 22100 Price Code: A03 


\title{
Technology Projections for Solar Dynamic Power
}

\author{
Lee S. Mason \\ NASA Lewis Research Center, Cleveland, OH 44135, (216) 977-7106 \\ Lee.Mason@lerc.nasa.gov
}

\begin{abstract}
Solar Dynamic power systems can offer many potential benefits to Earth orbiting satellites including high solar-to-electric efficiency, long life without performance degradation, and high power capability. A recent integrated system test of a 2 kilowatt SD power system in a simulated space environment has successfully demonstrated technology readiness for space flight. Conceptual design studies of SD power systems have addressed several potential mission applications: a 10 kilowatt LEO satellite, a low power Space Based Radar, and a 30 kilowatt GEO communications satellite. The studies show that with moderate component development, SD systems can exhibit excellent mass and deployed area characteristics. Using the conceptual design studies as a basis, a SD technology roadmap was generated which identifies the component advances necessary to assure SD systems a competitive advantage for future NASA, DOD, and commercial missions.
\end{abstract}

\section{BACKGROUND}

Solar Dynamic (SD) power systems concentrate sunlight into a receiver where the energy is transferred to a heat engine for conversion to electrical power. As shown schematically in Figure 1, the heated fluid from the receiver is circulated through a power conversion unit where electrical power is generated from heat. The waste heat is removed through a heat exchanger and dissipated by radiator panels to space. A power management and distribution (PMAD) system converts the heat engine's electrical output as required by the spacecraft bus and maintains control of the SD system operation. The state-of-the-art power conversion technology for space SD systems is based on the closed Brayton cycle. Brayton cycle systems utilize a turbine, compressor and rotary alternator to generate electrical power using an inert gas working fluid. A recuperative heat exchanger between the turbine discharge and receiver inlet is used to improve cycle efficiency. Other power conversion technologies that could be used in SD power systems include Stirling and Rankine cycles. Generally, SD systems are considered to offer the benefits of high solar-to-electric efficiency, long life without performance degradation, and high power capability. Long life is made possible through the use of non-contacting gas bearings, hermetic sealing of the gas circuit, redundant electronic components, and ultraviolet/atomic oxygen protective coatings on all optical surfaces. Radiation degradation is reduced relative to solar photovoltaic arrays since semi-conducting materials are not used on the large exposed surfaces.

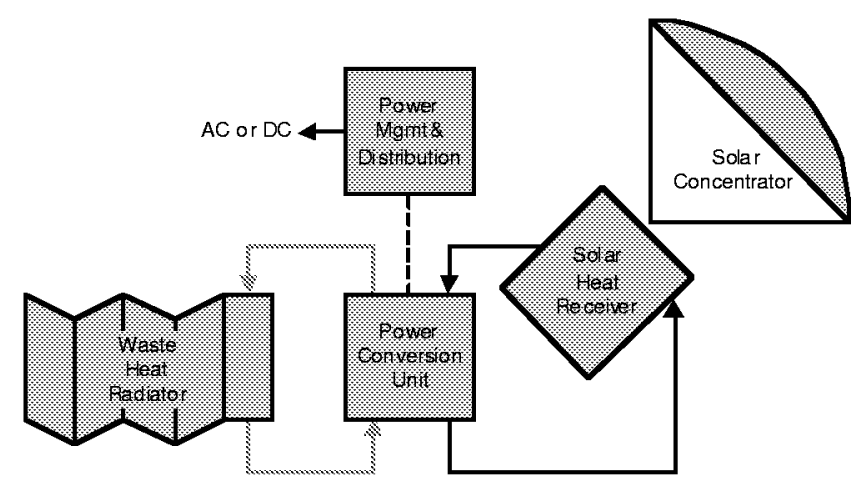

FIGURE 1. Solar Dynamic Power System Schematic. 


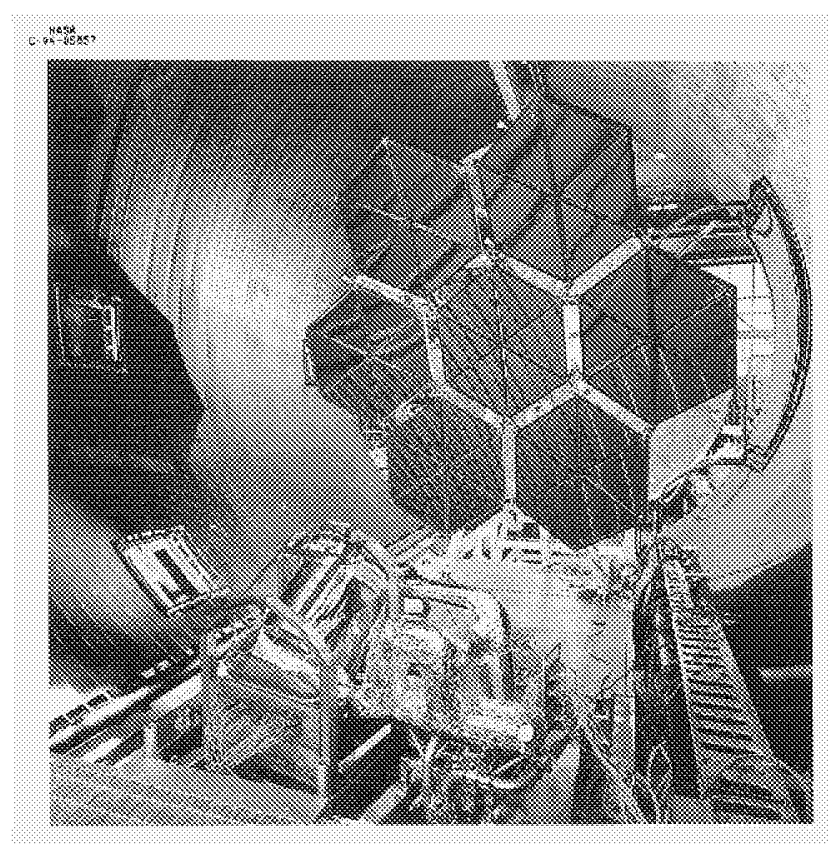

FIGURE 2. Solar Dynamic Ground Test Demonstration at NASA Lewis.

\section{Solar Dynamic Ground Test Demonstration}

A Ground Test Demonstration (GTD) of a $2 \mathrm{~kW}$ SD space power system, shown in Figure 2, was recently completed at the NASA Lewis Research Center. The test included an off-axis solar concentrator, heat receiver with thermal energy storage (TES), recuperated-Brayton cycle heat engine, and waste heat radiator in a thermal vacuum environment. The TES, a $\mathrm{LiF}-\mathrm{CaF}_{2}$ phase change material contained in canisters surrounding the gas flow tubes, was used to heat the working fluid during the eclipse to allow continuous power production through the orbit, eliminating the need for recharagable batteries. The testing was conducted with a solar simulator to provide a complete solar-to-electrical system demonstration. Cycle efficiencies (ratio of alternator power to heat input) of the Brayton unit were measured at $29 \%$ and orbital efficiencies (ratio of electrical energy output to solar energy collected over an orbit) were measured at 17\%. From 1994 to 1998, the system had accumulated nearly 800 hours of operation including 33 ambient start-ups and 372 orbit cycles (Shaltens, 1999).

A flight version of the $2 \mathrm{~kW}$ system, which utilized a similar receiver and Brayton engine to the ground test system and a Russian designed concentrator and radiator, was planned for 1998 but was cancelled due to Shuttle manifest changes. A significant portion of the flight receiver, engine, and controls were completed prior to the project's cancellation and some of the flight development hardware was integrated with the GTD testbed for performance characterization. Allied Signal Aerospace Systems Equipment, Tempe, Arizona served as prime contractor for both the GTD and Flight Demonstration projects.

\section{TECHNOLOGY ROADMAP}

Currently, there are no specific programs in SD technology development. However, there are related programs in advanced solar concentrators and high efficiency heat engines. The solar concentrator efforts are supported through the Air Force Research Laboratory (AFRL) Solar Orbit Transfer Vehicle (SOTV) project. SOTV is a flight experiment of a solar thermal propulsion system. Advanced concentrator development is aimed at high efficiency, lightweight, deployable systems using either inflatable or spline radial panel (SRP) technology. The major companies involved in concentrator development include SRS Technologies in Huntsville, Alabama and Harris Corporation in Melbourne, Florida. An associated project, Advanced Solar Concentrator Technology (ASCoT), has been proposed as a piggy-back experiment on SOTV to further develop the optics 
system of a solar thermal propulsion system using a refractive secondary concentrator in tandem with an inflatable fresnel primary.

Free-piston Stirling convertors are being pursued as an advanced power conversion system for various NASA and DOD missions. Advanced, high efficiency engine development is being leveraged from terrestrial power programs. Stirling Technology Company (STC) in Kennewick, Washington has successfully designed, built, and operated free-piston convertors at 10 watts and 350 watts. STC is also developing a 55 watt Technology Demonstration Convertor (TDC), to be used in a four engine configuration, as an alternative power conversion system for the Advanced Radioisotope Power System (ARPS) project (White, 1999). All of these engines share common technology characteristics including flexure bearings. The 10 watt engine has undergone endurance testing to over 45,000 hours. A key technical hurdle, parallel engine operation with thermodynamically independent converters, has been demonstrated with the 350 watt STC engines. Another technical objective, dynamic vibration compensation, is already being addressed through a Small Business Innovation Research (SBIR) grant with STC. In addition, the Applied Research Laboratory at Penn State University expects to demonstrate a combined Stirling and flywheel system in a breadboard configuration for a future U.S. Navy application.

The SD GTD test program demonstrated the performance potential of SD systems but did not address the weight goals needed to compete with advanced solar photovoltaic and battery systems. The program elements of a mass competitive SD power system development would include 1) a lightweight, deployable solar concentrator (already being addressed in the SOTV program), 2) a sodium heat pipe, heat receiver with LiF phase change material, and 3) a lightweight, composite radiator. The advanced concentrator, either inflatable or SRP, reduces the areal density of the SD concentrator by a factor of five from $10 \mathrm{~kg} / \mathrm{m}^{2}$ for conventional rigid panel concentrators to less than $2 \mathrm{~kg} / \mathrm{m}^{2}$. Both concentrator technologies also provide reduced stowage volume and autonomous deployment. A heat pipe receiver with $\mathrm{LiF}$ TES reduces the specific weight of a SD heat receiver by a factor of two from $10 \mathrm{~kg} / \mathrm{kWt}$ for conventional tube and canister receivers with $\mathrm{LiF}-\mathrm{CaF}{ }_{2}$ to less than $5 \mathrm{~kg} / \mathrm{kWt}$. Heat pipe receivers also allow higher cavity flux levels, and greater flux variation easing the pointing/surface accuracy requirements of the concentrator. A modest increase in the peak cycle temperature from $1033 \mathrm{~K}$ to $1100 \mathrm{~K}$ accompanies the change from $\mathrm{LiF}-\mathrm{CaF}_{2}$ to $\mathrm{LiF} \mathrm{TES}$. A composite radiator reduces the areal density of the $\mathrm{SD}$ heat rejection system by a factor of two from $12 \mathrm{~kg} / \mathrm{m}^{2}$ for conventional aluminum panels to $6 \mathrm{~kg} / \mathrm{m}^{2}$.

An additional program element, particularly suited to lower power requirements, is free-piston Stirling energy conversion. Free-piston Stirling convertors utilize a power piston, displacer, and linear alternator to produce electrical power using a high pressure, inert gas working fluid. The use of Stirling rather than Brayton, has the combined effect of increasing conversion cycle efficiency and increasing the effective radiator temperature, resulting in a smaller concentrator and radiator.

\section{Cost Projections}

The Design, Development, Test and Engineering (DDT\&E) costs associated with the SD component advances described previously, were estimated based on contractor rough-order-of-magnitude (ROM) quotes. The cost quotes were based on a $2 \mathrm{~kW}$ system, but are applicable up to about 7 to $10 \mathrm{~kW}$. The total DDT\&E costs for developing all the major SD components was between $\$ 9 \mathrm{M}$ and $\$ 14 \mathrm{M}$ depending on concentrator and heat engine technology. Due to the suitability of SD components to mass production, low system recurring costs are also projected. The SRP concentrator, representing the highest component cost at $\$ 6 \mathrm{M}$, was twice the cost of a thin film, inflatable concentrator $(\$ 3 \mathrm{M})$. The large variation is the result of a cost versus risk trade-off. The SRP structure and deployment system is expected to have less development risk due to its similarity to RF antenna systems already being built for commercial applications. Alternatively, inflatable concentrators, which are projected to be less expensive and easier to fabricate, have never been fully demonstrated and therefore present a somewhat greater development risk. The heat pipe receiver $(\$ 4 \mathrm{M})$ and composite radiator (\$2M) efforts would draw heavily from technology development from the 1980's. The Stirling costs, projected at $\$ 2 \mathrm{M}$, represent the funding required to take a commercial, terrestrial engine which has already been developed and modify it for space. A ground test of the advanced development components as an integrated system would be desirable to verify system performance prior to a flight hardware production. The test could be conducted in the large solar-thermal/vacuum facility used for the SD GTD system testing. 


\section{MISSION CASE STUDIES}

In order to quantify the performance benefits of these advanced components, several mission case studies were devised. The LEO mission is meant to represent the class of satellite being considered for either NASA Earth science or broadband communications. The low power SBR mission is based on the Discoverer II satellite under development by the Air Force, DARPA, and NRO. The high power GEO mission is intended to represent the next generation of global digital communications satellites. All of the studies included a thermodynamic optimization of the heat engine efficiency for minimum system mass. The optimization represents a trade-off of heat source mass (concentrator and receiver) versus radiator mass. Higher efficiency results in a smaller heat source, but lower heat rejection temperature which leads to larger radiators. Lower efficiency yields a high heat rejection temperature to reduce radiator size at the expense of a larger heat source. The overall system mass includes the concentrator, receiver, heat engine, radiator, and PMAD to supply $120 \mathrm{Vdc}$ to the spacecraft bus.

\section{LEO Mission}

Future NASA and commercial satellites planned for LEO are expected to range in power from 100's of watts up to $10 \mathrm{~kW}$. The use of electric propulsion for station keeping or orbit insertion may increase power levels. Examples of planned LEO satellites include the NASA EOS AM-1 and PM-1 satellites at $2.5 \mathrm{~kW}$ and $5 \mathrm{~kW}$, respectively and the Teledesic broadband satellite system, estimated at 6 to $10 \mathrm{~kW}$ per satellite.

Table 1 shows the projected performance of a $10 \mathrm{~kW}$ SD power system for a $500 \mathrm{~km}$ circular LEO with a 95 minute orbit period and 36 minute eclipse. The SD system includes TES for continuous sun/eclipse power production and a 10 year system life was assumed. The reference, state-of-the-art (SOA) system assumes a rigid concentrator, tube and canister receiver with $\mathrm{LiF}-\mathrm{CaF}_{2} \mathrm{TES}$, and an aluminum panel radiator. The addition of an advanced concentrator in case $1 \mathrm{~A}$ provides a $40 \%$ increase in specific power. The optimized cycle efficiency is lower with the reduction in the relative mass of the heat source, but accompanies a decrease in the radiator area. Further reduction in the heat source mass is realized with the introduction of an advanced, heat pipe receiver and $\mathrm{LiF}$ TES as shown in case $1 \mathrm{~B}$. The specific power improves an additional $40 \%$ and the total deployed area (concentrator and radiator) is reduced by $15 \%$, relative to the reference case. Case $1 \mathrm{C}$ shows that a SD Brayton system with all advanced components can achieve a system specific mass approaching $12 \mathrm{~W} / \mathrm{kg}$. The use of free-piston Stirling conversion with the advanced components, in case 1D, improves the specific power to $15 \mathrm{~W} / \mathrm{kg}$ while reducing the deployed area by $25 \%$ relative to the all-advanced Brayton case.

\section{Space Based Radar Mission}

There are several different concepts for Earth orbital Space Based Radar (SBR) missions. Discoverer II is a relatively low power radar demonstration of Synthetic Aperture Radar (SAR) and Ground Moving Target Indication (GMTI), A two satellite demonstration in 2003 is planned as a precursor to a 24-48 satellite objective system in the 2007 to 2010 timeframe. The planned orbit altitude is $770 \mathrm{~km}$ which relates to a 100 minute orbit period and a 35 minute maximum eclipse, and the system design life is 7 to 10 years.

TABLE 1. SD Performance for $10 \mathrm{~kW}$ LEO Mission.

\begin{tabular}{|l|c|c|c|c|c|}
\hline Case & Ref & $\mathbf{1 A}$ & $\mathbf{1 B}$ & $\mathbf{1 C}$ & ID \\
\hline Concentrator & SOA & Advanced & Advanced & Advanced & Advanced \\
Receiver & SOA & SOA & Advanced & Advanced & Advanced \\
Radiator & SOA & SOA & SOA & Advanced & Advanced \\
Power Conversion & Brayton & Brayton & Brayton & Brayton & Stirling \\
\hline Cycle Efficiency & $32.7 \%$ & $30.4 \%$ & $30.3 \%$ & $33.8 \%$ & $42.0 \%$ \\
Concentrator $\left(\mathrm{m}^{2}\right)$ & 61.9 & 61.3 & 62.5 & 56.8 & 50.9 \\
Radiator $\left(\mathrm{m}^{2}\right)$ & 33.5 & 28.6 & 21.0 & 25.9 & 11.7 \\
System Mass $(\mathrm{kg})$ & 1984 & 1415 & 1028 & 870 & 665 \\
Specific Power $(\mathrm{W} / \mathrm{kg})$ & 5.0 & 7.1 & 9.7 & 11.5 & 15.0 \\
\hline
\end{tabular}


TABLE 2. SD Performance for Low Power Space Based Radar.

\begin{tabular}{|l|c|c|c|c|}
\hline Case & Ref & 2A & 2B & 2C \\
\hline Concentrator & SOA & Advanced & Advanced & Advanced \\
Receiver & SOA & Advanced & Advanced & Advanced \\
Radiator & SOA & Advanced & Advanced & Advanced \\
Power Conversion & Brayton & Brayton & Brayton & Stirling \\
Peak Power Source & TES & TES & Flywheels & Flywheels \\
\hline & & & & \\
\hline Cycle Efficiency & $31.4 \%$ & $31.3 \%$ & $24.4 \%$ & $36.3 \%$ \\
Concentrator $\left(\mathrm{m}^{2}\right)$ & 18.9 & 17.8 & 9.8 & 7.6 \\
Radiator $\left(\mathrm{m}^{2}\right)$ & 10.1 & 7.6 & 3.1 & 1.6 \\
System Mass $(\mathrm{kg})$ & 689 & 361 & 275 & 129 \\
Specific Power $(\mathrm{W} / \mathrm{kg})$ & 1.2 & 2.3 & 3.1 & 6.5 \\
\hline
\end{tabular}

Most SBR missions share a common characteristic power profile. Power levels are low for the majority of the orbit while the satellite is in standby mode. When the satellite acquires a target, the power requirements increase for radar operation. While the Discoverer II mission requirements are still evolving, early power estimates indicate a 400 watt standby level and $4.8 \mathrm{~kW}$ peak during radar operation. The radar duty cycle is estimated at $10 \%$ or approximately 10 minutes per orbit, resulting in an orbit average power of 850 watts.

The projected performance of SD-based power systems for the Discoverer II mission are presented in Table 2. The first two cases assume the use of TES to satisfy the radar peak requirement. This approach requires the concentrator and radiator be sized for the peak power demand and the SD power conversion system adjust to load power changes through speed or gas inventory control. As before, the reference case assumes a rigid concentrator, tube and canister receiver with $\mathrm{LiF}-\mathrm{CaF}_{2}$, and an aluminum panel radiator. Specific power, defined as the ratio of average orbital power to total power system mass, is only $1.2 \mathrm{~W} / \mathrm{kg}$ as a result of the oversized system. Case $2 \mathrm{~A}$ shows the expected performance of an all advanced component Brayton with $\mathrm{LiF}$ TES, providing a nearly $2 x$ increase in specific power over the reference.

An option to using TES for the radar peak is to use auxiliary energy storage to augment the SD system, such as flywheels (Christopher, 1998). In this case, the SD receiver would have sufficient TES to maintain a constant sun/eclipse power output and the flywheels would supply the additional power for the radar peak. The Discoverer II power profile would demand a $1 \mathrm{~kW}$ SD system for standby power and flywheel charging, and $0.65 \mathrm{~kW}$-hrs of flywheels for peak power augmentation. The benefit of auxiliary energy storage is evident in case $2 \mathrm{~B}$, with improvements of $30 \%$ in specific power and $50 \%$ in deployed area relative to the all-advanced component Brayton/TES case. The substitution of Stirling conversion in case $2 \mathrm{C}$, which is very well suited to this power level, provides a 30\% reduction in deployed area and a 110\% increase in specific power versus the Brayton/flywheel case. The generally poor values of specific power for all the cases are representative of the challenging power profile associated with SBR type missions.

\section{GEO Mission}

The power requirements for future GEO communications satellites are expected to reach $30 \mathrm{~kW}$. Power levels continue to rise as manufacturers increase the number and size of communication transponders on each satellite to expand revenue potential. Loral and Hughes are both developing future GEO satellites to meet increasing power demands. The most difficult challenge for a GEO solar power system is satisfying the long maximum eclipse period. On a yearly basis, GEO satellites experience an increasing solar eclipse from several minutes up to a maximum of 70 minutes of the 24 hour orbit period.

The $30 \mathrm{~kW}$ projected demand would be best satisfied by two $15 \mathrm{~kW}$ SD units. The performance projections for a $15 \mathrm{~kW}, 10$ year life, GEO SD power module are provided in Table 3. Similarly to the SBR mission, auxiliary energy storage was considered as an option to TES, for the eclipse period. The flywheel energy storage requirement for a $15 \mathrm{~kW}$ GEO power module is $17.5 \mathrm{~kW}$-hrs. The reference case with SOA components and TES results in a specific power of $4.7 \mathrm{~W} / \mathrm{kg}$. The use of an advanced concentrator, receiver, and radiator in case $3 \mathrm{~A}$ improves the specific power by more than a factor of two, but still results in an 
TABLE 3. SD Performance for $15 \mathrm{~kW}$ GEO SD Module.

\begin{tabular}{|l|c|c|c|c|}
\hline Case & Ref & 3A & 3B & 3C \\
\hline Concentrator & SOA & Advanced & Advanced & Advanced \\
Receiver & SOA & Advanced & Advanced & Advanced \\
Radiator & SOA & Advanced & Advanced & Advanced \\
Power Conversion & Brayton & Brayton & Brayton & Stirling \\
Eclipse Power Source & TES & TES & Flywheels & Flywheels \\
\hline & & & & \\
\hline Cycle Efficiency & $33.9 \%$ & $35.9 \%$ & $27.8 \%$ & $37.0 \%$ \\
Concentrator $\left(\mathrm{m}^{2}\right)$ & 56.5 & 50.3 & 60.8 & 53.1 \\
Radiator $\left(\mathrm{m}^{2}\right)$ & 54.0 & 45.1 & 27.4 & 10.0 \\
System Mass $(\mathrm{kg})$ & 3174 & 1524 & 1150 & 973 \\
Specific Power $(\mathrm{W} / \mathrm{kg})$ & 4.7 & 9.8 & 13.7 & 16.2 \\
\hline
\end{tabular}

unwieldy heat receiver at $722 \mathrm{~kg}$ (out of $1524 \mathrm{~kg}$ total) due to the excessive thermal energy storage requirement for eclipse. If the receiver TES were eliminated and flywheels were used for the eclipse period, system specific power for an advanced component Brayton system improves to nearly $14 \mathrm{~W} / \mathrm{kg}$. While a 15 $\mathrm{kW}$ power module may be somewhat large for the STC class of Stirling convertors, case 3C presents the estimated performance of a Stirling/flywheel system for GEO. As was the result for the previous Stirling cases, substantial benefits can be realized in both specific power and deployed area.

\section{CONCLUSION}

Solar dynamic systems represent the next generation of advanced space power providing long life, reduced deployed area, and high power capability. Integrated system tests have demonstrated the performance potential of SD power. Advanced component development will provide the necessary system mass improvements to assure competitiveness with other advanced power technologies. SD technology is well suited for a wide range of Earth orbiting mission applications including low, medium, and geo-synchronous Earth orbit, with and without power peaking. For a modest development investment, SD systems could achieve system specific power levels greater than $10 \mathrm{~W} / \mathrm{kg}$ with Brayton conversion and greater than $15 \mathrm{~W} / \mathrm{kg}$ with Stirling conversion.

\section{REFERENCES}

Christopher, D.A., and Donet, C., "Flywheel Technology and Potential Benefits for Aerospace Applications," Proceedings from the IEEE Aerospace Conference, 1998.

Shaltens, R.S., and Mason, L.S., "800 Hours of Operational Experience from a 2 kWe Solar Dynamic System," Proceedings of the Space Technology and Applications International Forum (STAIF-99), 1999.

White, M.A., Qui, S., Olan, R.W., and Erbeznik, R.M., "Technology Demonstration of a Free-Piston Stirling Advanced Radioisotope Space Power System," Proceedings of the Space Technology and Applications International Forum (STAIF-99), 1999. 
Public reporting burden for this collection of information is estimated to average 1 hour per response, including the time for reviewing instructions, searching existing data sources, gathering and maintaining the data needed, and completing and reviewing the collection of information. Send comments regarding this burden estimate or any other aspect of this collection of information, including suggestions for reducing this burden to Washington Headquarters Services. Directorate for Information Operations and Reports, 1215 Jefferson Davis Highway, Suite 1204, Arlington, VA 22202-4302, and to the Office of Management and Budget Paperwork Reduction Project (0704-0188), Washington, DC 20503.

\begin{tabular}{|l|l|l}
\hline 1. AGENCY USE ONLY (Leave blank) & $\begin{array}{c}\text { 2. REPORT DATE } \\
\text { January } 1999\end{array}$ & $\begin{array}{r}\text { 3. REPORT TYPE AND DATES COVERED } \\
\text { Technical Memorandum }\end{array}$ \\
\hline
\end{tabular}

\section{TITLE AND SUBTITLE}

\section{FUNDING NUMBERS}

WU-632-1A-1D-00

\section{AUTHOR(S)}

Lee S. Mason

\section{PERFORMING ORGANIZATION NAME(S) AND ADDRESS(ES)}

National Aeronautics and Space Administration

Lewis Research Center

Cleveland, Ohio 44135-3191

8. PERFORMING ORGANIZATION REPORT NUMBER

E-11473

\section{SPONSORING/MONITORING AGENCY NAME(S) AND ADDRESS(ES)}

National Aeronautics and Space Administration

Washington, DC 20546-0001

10. SPONSORING/MONITORING AGENCY REPORT NUMBER

NASA TM-1999-208851

\section{SUPPLEMENTARY NOTES}

Prepared for the Space Technology and Applications International Forum cosponsored by the Boeing Company, Lockheed Martin, National Aeronautics and Space Administration, U.S. Air Force, and the U.S. Department of Energy, Albuquerque, New Mexico, January 31-February 4, 1999. Responsible person, Lee S. Mason, organization code 5490, (216) 433-7106.

Unclassified - Unlimited

Subject Categories: 18 and 20

Distribution: Nonstandard

This publication is available from the NASA Center for AeroSpace Information, (301) 621-0390.

\section{ABSTRACT (Maximum 200 words)}

Solar Dynamic power systems can offer many potential benefits to Earth orbiting satellites including high solar-to-electric efficiency, long life without performance degradation, and high power capability. A recent integrated system test of a 2 kilowatt SD power system in a simulated space environment has successfully demonstrated technology readiness for space flight. Conceptual design studies of SD power systems have addressed several potential mission applications: a 10 kilowatt LEO satellite, a low power Space Based Radar, and a 30 kilowatt GEO communications satellite. The studies show that with moderate component development, SD systems can exhibit excellent mass and deployed area characteristics. Using the conceptual design studies as a basis, a SD technology roadmap was generated which identifies the component advances necessary to assure SD systems a competitive advantage for future NASA, DOD, and commercial missions.

\section{SUBJECT TERMS}

Solar power; Solar dynamic; Brayton cycle; Stirling cycle

\begin{tabular}{|c|c|}
\hline 17. SECURITY CLASSIFICATION & 18. SECURITY CLASSIFICATION \\
OF REPORT & OF THIS PAGE \\
Unclassified & Unclassified
\end{tabular}

NSN 7540-01-280-5500
15. NUMBER OF PAGES

12

16. PRICE CODE

19. SECURITY CLASSIFICATION 20. LIMITATION OF ABSTRACT OF ABSTRACT

Unclassified 